\title{
Development of TOSRA (Test of Science Related Attitudes) Instrument for Science Related Attitude Studies in Sindh Province
}

\author{
Zohra Khatoon $^{1}$, Ameer Ali Buriro ${ }^{2}$, Sakina Jumani ${ }^{3}$ \\ Abstract

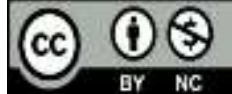

This study aims to explore the implementation of attitude measurement tool known as Test of Science-Related Attitudes (TOSRA) in Sindh. 1097 highersecondary level students from Hyderabad division of Sindh participated in the study. The alpha reliability values of different scale of TOSRA were analysed and enhanced to acceptable and good level using statistical techniques. The alpha coefficients for adapted TOSRA scales were observed as; Social Implications of Science (0.707), Adoption of Scientific Attitudes (0.801), Classroom Enjoyment (0.779), Leisure Interest in Science (0.767) and Career Interest in Science (0.701). The overall alpha coefficient for adopted (five-scale) TOSRA questionnaire administered in this study was 0.912. Similarly, the values of discriminant validity of the scales were deduced using correlation techniques for these scales where mean correlation between the scales ranged from 0.49 to 0.57 . The adopted version of TOSRA was developed based on the statistical analyses including Cronbach alpha, Pearson's correlation, and factor analysis, and showed sufficient validity and reliability to be implemented in subsequent research to measure students' attitude towards science in province of Sindh, Pakistan.

Keywords: Attitude towards Science, TOSRA, Instrument development, Science Education, Higher secondary students

\section{Introduction}

In recent past, many educationists and psychologists have focused on attitude research because of the perceived relationship between attitudes towards science and other characteristics such as students' behaviour to science, academic performance and career choices (Hill, 1990). Attitude of an individual is acquired by his or her direct or indirect experience and is subject to change. The attitude of a person can be directed to an abstract idea, policy or issue or a person or group. According to (Wrightsman, 1977) the variation of an attitude is

\footnotetext{
${ }^{1}$ Assistant Professor Department of Science and Technical Education University of Sindh, Jamshoro Email: zohra.khowaja@usindh.edu.pk

${ }^{2}$ Assistant Professor, Institute of Gender Studies, University of Sindh, Jamshoro Email: ameer.buriro@usindh,edu.pk

${ }^{3}$ Lecturer, Department of Education, University of Sufism and Modern Sciences, Bhitshah Email: sakinajumani00@gmail.com
} 
possible and linked to its specificity. Despite attitude is susceptible to change, (Koballa, 1988) was of opinion that; it does not happen randomly but a specific event is required to trigger the change. The definition of "attitude" itself has emerged as a tricky part of the attitude studies towards science conducted by (Germann, 1988; Francis, 1999). In everyday life, people use the term "attitude" commonly but everyone has their own meanings, concepts and definitions. Many common human aspects such as self-esteem, feelings, motivation, enjoyment, etc., related to attitudes, may or may not be counted in the definition of attitude. According to Koballa (1988) the term attitude was first used by (Thomas \& Znaniecki, 1918) in early $18^{\text {th }}$ century, in the field of psychology. Thurstone (1928) describe attitude as "someone's overall ideas, fears, threats, leaning, feelings, prejudice, bias, beliefs and convictions about any specified subject". Thurstone (1946) finally modified his previous definitions and described attitude as "the intensity of positive or negative effect" for or against a psychological subject. No direct method exists to measure attitudes directly; the only way it can be inferred from its consequences. Eagly \& Chaiken (1993) describe definition of attitude as "a psychological tendency that is expressed by evaluating a particular entity with some degree of favour or disfavour". "Attitudes are reinforced by beliefs (the cognitive component), often attract strong feelings (the emotional component) which may lead to particular behavioural events the action component" (p.75). Reid (2006) provided clear definitions of the above components as follows:

1) Cognitive: ideas component; knowledge about the subject, the beliefs,

2) Affective: like or dislike component; a feeling about the subject, and

3) Behavioural: the objective component; a tendency-towards-action.

The distinction between attitude and behaviour can be made clear here. The attitude, by definition, involves mind's affinity to certain values and ideas; while the behaviour is associated to the actual reflection of feelings. In fact, it has always been difficult to separate many affective and cognitive concepts. Nevertheless, attitude is defined on the basis of affective components by some researchers (Germann, 1988; George, 2001). Whereas other researchers are of opinion that attitude is individuals' beliefs about the attributes of a subject. Therefore, attitude and affective components of attitude are connected to individual's' beliefs (Fishbein \& Ajzen, 1975). We can conclude the definition of attitude based on above discussion and use it in this study as; "attitude is individuals' feelings about a subject, based on their beliefs about the subject."

\subsection{Objectives of the Study}

The attitude measurement tool known as TOSRA- Test of Science Related Attitudes has never been utilised for attitude studies ever conducted in 
Sindh province. The TOSRA-Test of Science Related Attitudes study has following objectives; that has been already achieve in this study.

1) The study will also provide answer whether TOSRA tool achieves satisfactory level of validity and reliability when it is used on school students in government schools in Sindh province.

2) This study would assist future researchers using TOSRA for assessing student's attitude towards science at different levels of school children.

3) The findings of this study will significantly impact relevant areas of science education, psychology and sociology.

However, this study consists of the above objectives where; TOSRA- which is known as an attitude measurement has been developed first time in educational study in Sindh province, hence this study does not have any hypothesis to test or research questions to answer. In TOSRA instrument, the above subscales based on Klopfer's classification (Klopfer, 1971) has been discussed meticulously.

\section{Literature Review}

Attitude doesn't have any physical component so it is substantially difficult to measure. However, it can be measured on inferences drawn from; self-reports of beliefs, feelings, and behaviours. However, in quantitative researches, the first; self-report measure approach is in common practice. The various methods of the measurement of attitude based in self-report technique are reviewed by (Gardener, 1975). Main approaches include; Attitude scales, Interest inventories, Preference ranking, Subject enrolment, Thurston's equal appearing interval Scale, Guttmann's Scale, Q-Sort scale and Staple Scale. From these approaches, measuring attitudes using "attitude scales" is considered as the most common method. This can be implemented in variety of ways such as differential scales, semantic differential scales, and summated rating scales. Summated rating scales consist of Likert-items, first developed by Likert (1932) in which a subject has to respond on a continuum rating scale, was used by (Fraser, 1981) for measuring the attitude of school children towards science using his famous TOSRA- Test of Science-Related Attitudes. This is considered as the most commonly used technique in which respondents are required to rate their opinion by usually choosing from three to seven-points cored scale such as 'strongly agree, agree, to some extent agree, neither agree nor disagree, to some extent disagree, disagree, strongly disagree. In order to increase the reliability of this method, researchers ask the respondents multiple questions on same construct. The reliability of this technique can be further enhanced by asking the positive and negative questions on the same construct and then scored according in the final summation. 
Despite many advantages to use attitude scales as discussed but still there are also some glitches and drawbacks associated with existing attitude measurements as discussed by various researchers like (Reid, 2006; Germann, 1988; Bennett, 2001). The lack of clarity pointed out by (Osborne et al., 2003) as "when we measure attitude towards science, the question is; what actually we are going to measure?" Therefore, the main source of confusion is deficiency of clarity and definition of what is being measured. All of these are measurements can vary considerably (Ramsden, 1998). Whereas, (Germann, 1988; Bennett, 2001) see the major cause of inconsistency between many instruments used for attitude measurement is caused by lack of definition and clarity of the construct. Therefore, it could be problematic to include items from different constructs in the same scale. A quality psychometric instrument fundamentally requires to be internally consistent and statistically unidimensional. The instrument items in a unidimensional scale by definition should measure the same construct hence considered as internally consistent. On contrary, not all internally consistent scales are unidimensional. The uni-dimensionality of a scale can be verified by a statistical technique known as factor analysis. Construct validity is also another important parameter to be considered. Construct validity normally refers to at what extent an instrument or tool measures the construct that it was supposed to measure. There are two types of construct validity: convergent and discriminant validity. Disregarding validity can be destructive and compromising the quality of psychometric study.

There are many attitude measuring tools available, the issue is that these instruments are developed in mostly foreign languages such as English language. Hence translation and adapted versions of these instruments lacks reliability and validity. To overcome this issue, in Pakistan's context, (Ahmad \& Mahmood, 2011) developed a tool to measure attititude towards science learning (AtSL). The academic argument behind development of this new tool, AtSL, was contextually relevant to uniqueness of socio-economic and cultural aspects of Pakistani society. Cronbach's alpha of the tool was 0.86 . The tool was administered to more than twelve hundred students of various government schools of three different districts in Punjab. Another study was conducted by (Anwer et al., 2012) to investigate the attitude towards science and test anxiety of $10^{\text {th }}$ grade students in Punjab province. Where he used his own modified and translated version of TOSRA to investigate the attitude towards science in a study conducted on $10^{\text {th }}$ class students in Punjab. The authors also verified reliability and validity of modified versions of TOSRA and TAI. The authors reported alpha reliability from 0.56 to 0.73 for sub scales of revised and modified version of TOSRA. The objectives of this study included to investigate students' 
attitude towards science and validate Urdu translation of the Test of ScienceRelated Attitudes (TOSRA-Urdu). Another researcher, (Rana, 2002) used TOSRA to measure higher secondary school students' attitudes toward science. $\mathrm{He}$ also translated the original version of TOSRA into Urdu language. All of the seven scales of TOSRA were used in the study with reliability coefficient value of 0.9104 .

The attitude towards science measurement instrument was originally developed by (Fraser, 1978). Numerous studies have been carried out using this instrument and hence widely tested and applied in the field of science education (Welch., 2010). Primarily, Fraser developed this instrument to evaluate science related interests and attitudes of middle and high school students. The test was consisting of seven sub-scales and comprises of ten Likert-type items per subscale (e.g. "I would prefer to find out why something happens by doing an experiment than by being told"). The seven attitude sub-scales are; Social implications of science, Normality of scientists, Attitude of science inquiry, Adoption of scientific attitudes, Enjoyment of science lessons, Leisure interests in science, and Career interests in science. In TOSRA instrument, the above subscales are based on Klopfer's classification (Klopfer, 1971). Here it is briefly explained as follows:

a. The Social Implications of Science subscale measures "the manifestation of favourable attitudes towards science". This part of the instrument explores participants' opinion about social pros and cons associated with scientific progress and development.

b. The Normality of Scientists subscale measures "the attitude toward scientists as normal people rather than eccentrics." This sub-scale explores individual's perception about the scientists' life style whether it normal or not.

c. The Attitude of Scientific Inquiry subscale measures "the attitude toward scientific experimentation and inquiry as methods of obtaining information about the natural world." In other words, this sub-scale explores individuals' level of scientific inquiry as a way of thinking process.

d. The Adoption of Scientific Attitudes subscale measures "the open-mindedness, willingness to reverse opinions related to scientific investigation and inquiry." This sub-scale measures persons' ability to how easily they alter their opinion by observing the world based on scientific evidences.

e. The Enjoyment of Science Lessons sub-scale measures "the enjoyment of science learning experiences." This scale explores the enjoyment level of students when they participate in science classes and perform experiments in science labs. 
f. The Leisure Interests in Science subscale measures "the development of interests in science and science-related activities." This sub-scale explores students' interest in science or science related activities when they are out of class room or lab.

g. The Career Interests in Science sub-scale measures "the student interests in pursuing a science career." This sub-scale enquires about the future plan of the students if they are going to pursue science as carrier when the finish school education.

First time (Fraser \& Fisher, 1982) conducted a study in which they administered TOSRA on more than hundred students of high school grade classes. TORSA has been tested in several public and private schools in Australia and America. The results of these surveys suggesting the scales have crosscultural validity (Fraser, 1981). In order to restrain a respondent to provide a set dogma, in TOSRA, statements on the scales are set to be moderately negative or positive. TOSRA statements are based on Likert-Type (Likert, 1932) in which participants will judge their level of agreement or disagreement with each statement on a five-point scale; (a) strongly agree, (b) agree, (c) not sure, (d) disagree, and (e) strongly disagree. In order to convert the Likert-Type survey to Likert-Scale; the statements' responses were allotted score of 5,4,3,2 and1 for the $\mathrm{a}, \mathrm{b}, \mathrm{c}, \mathrm{d}$, and e options respectively, for items/statements designated as positive $(+)$. Whereas score points $1,2,3,4$, and 5 were allotted to a, b, c, d, and e responses respectively for those items which were designated as negative (-) statements. At the end, scored items were added together to obtain the overall value for the scale.

\subsection{Participants and Setting}

\section{Research Methodology}

The participants of this study were higher secondary grade (intermediate level) students belonging to Class XI \& XII who were taking science subjects; Mathematics, Biology, Chemistry, Physics and Computer science, as their majors. The participants were from various districts of Hyderabad Division of Sindh province. For this study, the statements of TOSRA were also translated in national language to avoid any confusion for the students. The participants were from various districts of Hyderabad Division of Sindh province. There are separate colleges or higher secondary schools for boys and girls in almost each taluka/tahsil headquarter of every district. In urban districts, such as Hyderabad has several public and private higher secondary institutes. Due to lack of information and central data base system of the educational institutes, it was difficult to get exact number of register students in the province per year. Hyderabad division in Sindh province consists of balanced proportion of rural 
and urban population as well as people from different socio-economic and ethnic backgrounds. Hence Hyderabad division represents multi-cultural society of Sindh province more than any other division.

\subsection{Sample Size}

For a research survey, it is very important to decide appropriate sample size for the study. The research instrument of this study was a based on Likertitem scale. The sample calculation for such type of survey is not straight forward as it depends on number of factors. Typical Likert-item scale survey mostly provides a statistical response based on Normal Distribution (Likert, 1932). Sample size "N" for a Likert-item scale survey depends on the following factors;

- Confidence interval " $\mathrm{z}_{\sigma}$ ": represents standard deviation of Normal distribution

- Coefficient of variation "C": less than 1 in Likert-item scale

- No. of items in the scale " $k$ ": ranges from 4-10

- Correlation between the items " $\rho$ ":

- Tolerable error " $D$ "

The reasonable sample size for Likert-item scale survey can be calculated using the following formula ; (Park \& Misook, 2009)

$N=\frac{z \sigma^{2} C^{2}}{k D^{2}}[1+(k-1) \rho]$

Where, $\mathrm{k}$ is number of items in the scale, $\rho$ is correlation between the items, $C$ is coefficient of variation, $\mathrm{z}_{\sigma}$ confidence interval and $D$ is tolerable error. In Likert-scale surveys, confidence level of 2-sigma (95\%) and tolerable error level of $2 \%$ is required. If we fix the number of Likert items $k$, the relationship of sample size $N$ with correlation coefficient and coefficient of variance will decide the size of the sample. In this relationship between the variable, it can be seen that the sample size increases rapidly by increasing the values of both coefficients. By keeping both coefficients at 0.5 level, for a 5-10 item based Likert-scale survey, the sample size was calculated to be above $\mathrm{N}=1000$.

\subsection{Survey Administration}

Procedures to administer the survey were consistent with those provided by the author of the TOSRA survey instrument (Fraser, 1981). The survey was group administered during the participants' science class during the mid of the academic year 2015-2016 and 2017-2018. The students were also briefed about the purpose of the study. Further, they were informed that their individual perception were kept confidential and would not affect their science grade and would not be shared with anyone else. Only the final overall survey results would be used for research purpose only and could be shared with policy makers. Before taking the survey an explanation of how to take the Likert-type scales was 
given and the students were guided to ensure their understanding about the test. Students were told they can stop at any time if they so desired. Students were also encouraged to ask questions at any time during the survey. This encouragement helped to minimize students' uncertainty about questions on the scale and to reduce the likelihood of their leaving a question unanswered.

No time limit was imposed for administration of the scale, though the original authors (Fraser, 1981) suggest younger students be expected to complete the scale in 30-45 min; while older students might require only $25-30 \mathrm{~min}$. On average, students finished the test within hour. This study was limited to Government higher secondary schools and colleges, and the students of First year and Second year classes (Intermediate level) taking Science subjects as major, commonly known as Pre-Engineering, Pre-Medical and Pre-Computer Science groups. This is a case study focusing urban and rural districts of Hyderabad division of Sindh province only. Ethical rules for researching humanitarian subjects are strictly followed in this study. In order to conduct the survey on the respondents, extreme care has been taken, so that no personal identity can be traced during and after the study. The respondents were not forced to participate in the study. The privacy, anonymity and confidentiality of the respondents were strictly followed in this study.

\subsection{Pilot Testing}

The TOSRA survey was pilot tested in October/November 2015 on a sample size of 315 students which was calculated according to the guidelines given by (Fraser, 1981). The sample for the pilot study was taken randomly from two/three different districts. The data obtained from the sample was analysed on rigorous statistical models including Alpha reliability, factor analysis and correlation.

\subsection{Alpha Reliability}

Alpha reliability test finds the conflicts in the positive and negative statement by finding the variation in the answers of the students. The value of alpha coefficient varies between 0 and 1 . High value of alpha coefficient suggests stronger correlation between the variables. The alpha coefficient of the original version was 0.876 . Table 3.5 shows the alpha coefficient for each scale before and after deleting those items which are affecting reliability of the scale. From this table, though the overall reliability was within acceptable range, but some scales have very low reliability in original 70 -item test. It can be concluded from the table that even deleting 5 or more items from subscale 2; Normality of scientist, still the value for alpha was not reliable. This result might be interpreted that the students do not have any idea or do not know much about a scientist's 
life. Same was true for subscale 3; Attitude of science inquiry. Similar results were obtaining in other studies conducted in Pakistan.

Table 3.5

Comparison of Alpha reliability scoring of TOSRA scales before and after deleting the items

\begin{tabular}{lccc}
\hline Seven attitude scales in TOSRA & $\begin{array}{c}\text { Alpha } \\
\text { coefficient } \\
\text { Pilot study }\end{array}$ & $\begin{array}{c}\text { After deleting } \\
\text { statements }\end{array}$ & $\begin{array}{c}\text { Improved } \\
\text { Alpha } \\
\text { coefficient }\end{array}$ \\
\hline Social implications of science & 0.580 & $1,15,36,50$ & .672 \\
Normality of scientists & 0.313 & $2,16,30,44,58$ & .530 \\
Attitude of science inquiry & 0.473 & $24,38,66$ & .547 \\
Adoption of scientific attitudes & 0.471 & $4,11,53,67$ & .601 \\
Enjoyment of science lessons & .785 & 0 & .785 \\
Leisure interests in science & .755 & 0 & .755 \\
Career interests in science & .672 & 7 & .743 \\
Note: Further deletion of items decreasing alpha values & & \\
\hline
\end{tabular}

\subsection{Correlation Analysis}

Correlation analysis shows that how the subscales in the questionnaire are related to each other. The correlation can be positive negative or zero and the values varies from +1 to -1 . Values above zero means the items are related positively if less than zero, mean items are negatively correlated, near zero value translated as there was no any correlation between the items. In TOSRA scales, items need to be positively correlated. The correlation between the sub-scales is shown in Table 2 where we can see that scale 2 is showing very low or even negative correlation in some cases. Whereas scale 3 is also showing little correlation with the other sub-scales. 
Table 3.6

Inter Item Correlation Matrix based on 70 item TOSRA

\begin{tabular}{cccccccc}
\hline $\begin{array}{c}\text { Correlation } \\
\text { Matrix }\end{array}$ & Scale 1 & Scale 2 & Scale 3 & Scale 4 & Scale 5 & Scale 6 & Scale 7 \\
\hline Scale 1 & 1.000 & -.014 & .320 & .470 & .635 & .578 & .491 \\
Scale 2 & -.014 & 1.000 & .008 & .019 & -.005 & .026 & .075 \\
Scale 3 & .320 & .008 & 1.000 & .417 & .312 & .277 & .371 \\
Scale 4 & .470 & .019 & .417 & 1.000 & .635 & .482 & .506 \\
Scale 5 & .635 & -.005 & .312 & .635 & 1.000 & .697 & .595 \\
Scale 6 & .578 & .026 & .277 & .482 & .697 & 1.000 & .564 \\
Scale 7 & .491 & .075 & .371 & .506 & .595 & .564 & 1.000 \\
\hline
\end{tabular}

\subsection{Analysis of Revised TOSRA}

Due to very low score on reliability test, from the above discussion it can be concluded that scale 2 and 3 can be excluded from the survey questionnaire based on TOSRA. Hence in the final survey, items related to scale 2 and 3 were taken out from the questionnaire. Further to this the scale items which needed to be deleted, in order to enhance the reliability of the rest of the sub-scales were also taken out, by doing so four items from each scale 1 and 4 were taken out, whereas one item was taken out from scale7. Hence, the revised TOSRA questionnaire based on 41 statements was finally carried out on the sample population of 1097 participants. Details of the deleted items are shown in the following table.

Table 3.7

Alpha coefficient for revised TOSRA subscales

\begin{tabular}{|c|c|c|c|c|c|c|}
\hline & Scale 1 & Scale 4 & Scale 5 & Scale 6 & Scale 7 & Total \\
\hline Initial Survey & 0.580 & .446 & 0.785 & 0.755 & 0.672 & $\begin{array}{l}0.87 \\
(7-\text { scale) }\end{array}$ \\
\hline Post Pilot survey & 0.707 & 0.801 & 0.779 & 0.767 & 0.701 & $\begin{array}{l}0.91 \\
(5 \text {-scale })\end{array}$ \\
\hline Fraser (1981) & 076 & 0.75 & 0.78 & 0.82 & 0.84 & $\begin{array}{l}0.78 \\
(7 \text {-scale) }\end{array}$ \\
\hline
\end{tabular}




\subsection{Reliability of Revised TOSRA}

The Alpha values of all subscales were increased significantly as shown in Table 3. Overall alpha score for TOSRA questionnaire also raised to 0.912 . Comparison with original TOSRA also given in the table.

\subsection{Correlation of Revised TOSRA}

Correlation analysis on the revised version of TOSRA was performed using SPSS functions. Error! Reference source not found. shows that how the revised subscales, 1, 4, 5, 6 and 7 in the revised TOSRA questionnaire are related to each other. The correlation between all scales is positive and statistically significant.

Table 3.9

Pearson Correlations of Revised TOSRA scales

\begin{tabular}{llllll}
\hline & Scale 1 & Scale 4 & Scale 5 & Scale 6 & Scale 7 \\
\cline { 2 - 6 } Scale 1 & 1 & $.635^{* *}$ & $.672^{* *}$ & $.551^{* *}$ & $.551^{* *}$ \\
Scale 4 & $.635^{* *}$ & 1 & $.664^{* *}$ & $.502^{* *}$ & $.502^{* *}$ \\
Scale 5 & $.672^{* *}$ & $.664^{* *}$ & 1 & $.627^{* *}$ & $.627^{* *}$ \\
Scale 6 & $.551^{* *}$ & $.502^{* *}$ & $.627^{* *}$ & 1 & $.631^{* *}$ \\
Scale 7 & $.551^{* *}$ & $.502^{* *}$ & $.627^{* *}$ & $.631^{* *}$ & 1 \\
$* *$ Correlation is significant at the 0.01 level (2-tailed). $(N=1097)$ & \\
\hline
\end{tabular}

\subsection{Factor Analysis}

Factor Analysis is a method extensively utilized in social sciences. In psychological constructs factor analysis is considered as a critical technique. Major use of factor analysis remained for the development of operational construct as well as representative of theoretical construct. Selection of underline major factors, in factor analysis method, is decided by Kaiser Eigenvalue criterion. According to this criterion, only factors having Eigen values one or greater than one will be selected for further interpretation. Various methods of factor analysis exist to extract a set of factors ordered according to the proportion of the variance of the original data. Hence, for further analysis, only a small set of factors or subset is retained and the rest of the instrument factors are omitted considering them either irrelevant or non-existent due to measurement error or noise. In order to extract reliable subset, Varimax rotation method is carried out to work out the internal structure of the revised TOSRA. According to this criterion only those items can be retained in an instrument whose score is 3.0 or higher in factor loading matrix.

In this study factor analyses using Principal Component Analyses (PCA) and orthogonal Varimax rotation were conducted to examine the internal 
structure of the adopted version of TOSRA based on 41 items. In statistics, factor

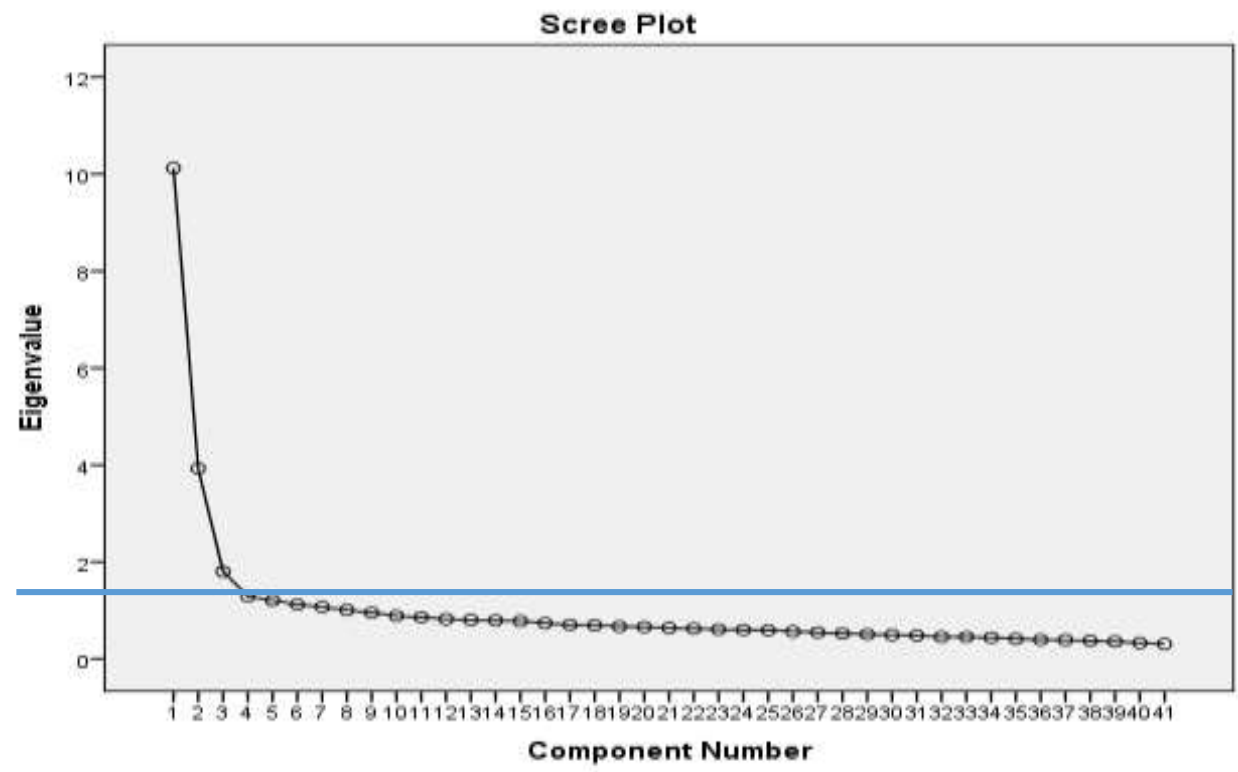

Figure 1: Scree plot of revised TOSRA

analysis works out underlying number of factors or dimension of the study being conducted. In other words, it finds that the questionnaire is looking for one or more than one underlying dependent variables. Overall factor analysis of adopted TOSRA should show 5 underlying factors; given that the original TOSRA investigates seven underlying scales as described earlier. First of all, it is important to verify that whether the data is suitable for Factor analysis or not, Kaiser-Meyer-Olkin (KMO) or Bartlett's Test of Sphericity, were conducted for sampling adequacy. The value of KMO; the measure of sampling adequacy was 0.946 , whereas the Bartlett's test of Sphericity was statistically significant with $\mathrm{p}$ $<.001$. This authenticates that the data can be used for factor analysis. The factor analysis based on principle component method is shown in the scree plot in Figure 1. In a scree plot only, those factors are significant whose Eigen values are above 1 (above guiding line in the figure). This plot also shows that there are 5 significant underline factors.

\subsection{Normality of data}

To assess the normality of the distribution of the TOSRA scales, the results of the Kolmogorov-Smirnov Normality test and Shaprio-Wilk were 
analysed. The results showed all the scales statistically significant value, $p<0.05$ which shows that we reject hypothesis of normality of data for all the scales. Though the normality tests suggested a violation of the assumption of normality, which is quite common in large samples (Pallant, 2010), the histogram of the scores still showed to be reasonably normally distributed in a bell shape and the Normal Q-Q plot of the scales showed scores in reasonably straight lines suggesting normal distribution.

\section{Results}

After pilot study, two scales of original TOSRA instrument, Normality of Scientists and Attitude to Science Inquiry were dropped due to low Cronbach Alpha reliability. Hence the revised version was consisting of 50 question statements and comprised of five scales. Overall alpha reliability value for revised TOSRA questionnaire was 0.912 . Whereas alpha reliability of TOSRA scales were ranging between 0.7 to 0.8 . Mean Correlation of a scale with other scales (Discriminant validity) was positive and ranging between 0.49 to 0.57 . KMO measure of sampling adequacy value was 0.946 and the Bartlett's test of Sphericity was $(\mathrm{p}<.001)$. Factor analysis based on principle component method with Varimax Rotation Technique revealed five underlying scale in the revised version of TOSRA. Q-Q Normal plots, Histogram analysis of the data revealed that the distribution of data was Normal.

\section{Discussion \& Conclusion}

From the findings of statistical analyses of pilot and post-pilot studies, it can be confirmed that internal consistency and reliability; measured as Cronbach alpha coefficient, and discriminant validity measured, as Correlation factor, of Test of Science-Related Attitudes (TOSRA) are valid and reliable. In the pilot testing conducted for this study conducted in Sindh province, the overall Cronbach alpha coefficient value for original format of Test of Science-Related Attitudes (TOSRA) was 0.87 whereas for the adopted version, based on five TOSRA sub-scales it was raised to 0.91. In other studies, conducted in Pakistan such as, (Rana, 2002) quoted alpha value of 0.914 for and an adopted version of TOSRA administered in Punjab province. In fact, most important values are; alpha values for individual TOSRA sub-scales. In this study, five scales (Seven in Pilot study) of TOSRA were used. In this study, the alpha coefficients for adapted five TOSRA scales were calculated as follows; Social Implications of Science (0.707), Adoption of Scientific Attitudes (0.801), Classroom Enjoyment (0.779), Leisure Interest in Science (0.767) and Career Interest in Science (0.701). Fraser (1981) provided average alpha values for Social Implications of Science (0.76), Adoption of Scientific Attitudes (0.75), Classroom Enjoyment (0.78), Leisure Interest in Science (0.82) and Career Interest in Science (0.84). 
The overall alpha coefficient for adapted (five-scale) TOSRA questionnaire administered in this study was 0.912 .

Likewise, the values of mean inter-correlation values for the adapted TOSRA scales in this study ranged from 0.49 to 0.57 which are in consistent to Fraser (1981) whose value ranged from 0.13 to 0.59 . Further to this principle factor analyses also conformed the five underlying scales with Eigen values $>1.0$. Hence it can be concluded that the instrument administrated on higher secondary students of Hyderabad division was valid and reliable and the required values were in consistence with original test developed by Fraser (1981) as well as similar studied conducted in Pakistan (Rana , 2002).

\section{Recommendation}

Further it is recommended that, in order to understand the attitude of students towards science, this study used five out of seven scales of TOSRA, in future studies, questionnaire or instrument should be adopted or developed in such a way that all of the scales should be used to understand the opinion of respondents. The reliability and validity of the questionnaire should be enhanced further as well. Secondly, this study was focused on the students of highersecondary level only. It is recommended that the similar type of research may be conducted on different levels, from primary to university level.

\section{References}

Ahmad, Z., \& Mahmood, N. (2011). Developing a Scale to Measure Attitude towards Science Learning among School Students. Bulletin of Education and Research, 33(1), 71-81.

Anwer., M., Hafiz, M. I., \& Christine, H. (2012,). Students' Attitude towards Science: A Case of Pakistan. Pakistan Journal of Social and Clinical Psychology, 10(1), 3-9.

Bennett, J. (2001). Science with attitude: the perennial issue of pupils" responses to science. School Science Review, 82(30), 59-67.

Eagly, A. E., \& Chaiken, S. (1993). The psychology of attitudes. Fort Worth, TX: Harcourt, 12(5), 459-466.

Fishbein, M., \& Ajzen, I. (1975). Belief, attitude, intention, behaviour: An introduction to theory and research. Reading, MA: Addison-Wesley.

Francis, L. J., \& Greer, J. E. (1999). Measuring attitude toward science among secondary school students: The affective domain. Research in Science \& Technological Education, 219-226. 
Fraser, B. J. (1981). Test of Sience-Related Attitudes ( $1^{\text {st }}$ ed.). Victoria: Australoian Council for Educational Research Ltd.

Gardener, P. L. (1975). Attitudes to science. Studies in Science Education, 2, 141.

George, J. M. (2001). Emotions and leadership: The role of emotional intelligence. Human Relations, 53, 1027-1055.

Germann, P. J. (1988). Development of the attitude toward science in school assessment and its use to investigate the relationship between science achievement and attitude toward science in school. JRST, 25(8), 689703.

Hill, O. e. (1990). Three studies of factors affecting the attitudes of blacks and females toward the pursuit of science and science related careers. Journal of Research in Science Teaching, 27, 289-314.

Klopfer, L. E. (1971). Evaluation of Learning in Science. New York: McGrawHill.

Koballa, Jr., T. R. (1988). Attitude and related concepts in science education. Science Education, 72(2), 115-126.

Likert, R. (1932). A technique for the measurement of attitudes. Archives of Psychology, 22(140), 1-55.

Osborne, J., Simon, S., \& Collins, S. (2003). Attitudes towards science: a review of the literature and its implication. International Journal of Science Education, 25(9), 1049-1079.

Pallant, J. (2010). SPSS survival manual: A step by step guide to data analysis using the SPSS program. New York.: McGraw Hill.

Park, J., \& Misook, J. (2009). Note on Determination of Sample Size for a Likert Scale. Communications of the Korean Statistical Society, 16(4), 669-673.

Ramsden, J. M. (1998). Mission impossible? Can anything be done about attitude to science? International Journal of Science Education, 20(2), 125-137.

Rana, R. A. (2002). Effect of parents' socioeconomic status, students' selfconcept and gender on science-related attitudes and achievement (Doctoral Thesis). Lahore: IER, University of the Punjab. 
Reid, N. (2006). Thoughts on attitude measurement. Research in Science \& Technological Education, 24(1), 3-27.

Thomas, G., \& Znaniecki, F. (1918). The Polish Peasant in Europe and America. Sociological Bulletin, 37(1/2), 11-31.

Thurstone, L. L. (1928). Attitudes can be measured. American Journal of Sociology, 33, 529-554.

Thurstone, L. L. (1946). Comment. American Journal of Sociology. American Journal of Sociology, 52, 39-52.

Welch., A. G. (2010). Using the TOSRA to Assess High School Students' Attitudes toward Science after Competing In the FIRST Robotics Competition: An Exploratory Study. Eurasia Journal of Mathematics, Science \& Technology Education., 6(3), 187-197.

Wrightsman, L. S. (1977). Social Psychology. Motery, CA: Brooks/Cole Publishing.

\section{Citation of this Article:}

Khatoon, Z., Buriro, A. A., \& Jumani, S. (2021). Development of TOSRA (Test of Science Related Attitudes) Instrument for Science Related Attitude Studies in Sindh Province. International Journal of Innovation in Teaching and Learning (IJITL), 7(1), 79-94. 